\title{
Fatores que influenciam a percepção de professores de enfermagem das competências na docência
}

\section{Factors influencing nursing teachers perceptions of competence in teaching}

\section{Factores que influyen la percepcion de los profesores de enfermería de las competencias en la docência}

\section{Recebido: 11/10/2015 \\ Aprovado: 07/03/2016 \\ Publicado: 01/05/2016}

\author{
Claudia Cristina Maciel dos Santos ${ }^{1}$ \\ Ana Claudia Giesbrecht Puggina² \\ Luciane Lúcio Pereira ${ }^{3}$
}

Este estudo teve como objetivo i dentificar os fatores que influenciam a percepção das competências para o exercício da docência. Pesquisa transversal quantitativo com 45 professores de graduação em enfermagem que responderam à "Escala de fatores que influenciam na percepção das competências para o exercício da docência". 0 escore médio total da escala foi de 170,6 $( \pm 13,7)$. Houve diferença estatisticamente significativa no fator Habilidades Interpessoais com atuação no Lato sensu (p-valor=0,03); nos fatores Abertura à Inovação e Apoio Proativo à Docência com atuação no Stricto sensu os valores foram idênticos (p-valor $<0,05)$. Os docentes participantes deste estudo tiveram uma percepção de moderada para alta da influência dos fatores na sua competência docente. Os professores que atuam no Lato sensu tiveram melhor percepção das suas habilidades interpessoais com os alunos; os que atuam no Stricto Sensu tiveram menor percepção em relação a suas habilidades de busca por inovações no ensino e apoio proativo ao aluno.

Descritores: Competência profissional; Ensino; Docentes de enfermagem.

The study aim was to identify factors that influence the perception of competences for practice of teaching. Quantitative transversal research with 45 undergraduate nursing professors who responded to "Scale of Factors Influencing the Perception of Competencies for the Practice of Teaching". The mean total scale score was $170.6( \pm 13.7)$. There was statistically significant difference in Interpersonal Skills factor in the variable performance in graduate Lato sensu (p-value=0.03); Innovation in Aperture and Proactive Support to Teaching factors with variable performance in graduate Stricto sensu the values were identical (p-value < 0.05). The teachers participating in this study had a perception of moderate to high influence of the factors in their teaching competence. Teachers who work in the Lato sensu had better perception of their interpersonal skills with students; those working in Stricto sensu had lower perceptions about their search skills for innovation in education and proactive support to the student.

Descriptors: Professional competence; Teaching; Faculty nursing.

Esto estudio tuvo como objetivo Identificar los factores que influyen la percepción de las competencias en la práctica docente. Investigación transversal y cuantitativa con 45 profesores de graduación de enfermería que respondieron a "Escala de factores que influyen en la percepción de las competencias para la práctica docente". La media de puntuación total de la escala fue 170,6 $( \pm 13,7)$. Hubo diferencia estadísticamente significativa en el factor de Habilidades Interpersonales en el rendimiento variable en postgrado Lato sensu (p-valor = 0,03); en los factores Apertura a la Innovación y el Apoyo Proactivo a la Docencia con un rendimiento variable en el grado Stricto sensu los valores fueran idénticos (p-valor $<0,05)$. Los profesores participantes en este estudio tenían una percepción de moderada a alta influencia de los factores en su competencia docente. Los profesores que trabajaban en el Lato sensu tenían una mejor percepción de sus habilidades interpersonales con los estudiantes; los que trabajaban en Stricto sensu tenían percepciones menores sobre sus habilidades de búsqueda de la innovación en la educación y el apoyo proactivo para el estudiante.

${ }^{1}$ Enfermeira. Especialista em Gerenciamento dos Serviços em Enfermagem e em Educação. Docente e Responsável Técnica do curso Técnico em Enfermagem do SENAC-Unidade Santo Amaro,SP, Brasil. claudia.cmsantos@sp.senac.br. Brasil.

${ }^{2}$ Enfermeira. Mestre e Doutora em Enfermagem na Saúde do Adulto. Pós Doutora em Enfermagem. Docente do Curso de Mestrado em Enfermagem da Universidade de Guarulhos. Professora Adjunta da Faculdade de Medicina de Jundiaí SP, Brasil. apuggina@prof.ung.br. Brasil.

${ }^{3}$ Enfermeira. Mestre e Doutora em Enfermagem. Docente do Curso de Mestrado em Enfermagem da Universidade de Guarulhos. Reitora da Universidade de Guarulhos, SP, Brasil. lucianeluciopereira@gmail.com. Brasil. 
Descriptores: Competencia profesional; Enseñanza; Docentes de enfermería.

\section{INTRODUÇÃO}

$\mathrm{A}_{\mathrm{s}}^{\mathrm{s}}$ Educação Superior no Brasil avançou significativamente nas últimas décadas e, passou por inúmeras mudanças, tanto no funcionamento institucional, configuração curricular, titulação dos docentes, institucionalização da pesquisa, produção intelectual, qualidade da formação oferecida, quanto na diversidade de ofertas de cursos e o aumento no número de estudantes e, desta forma, surge a necessidade de maior contingente e capacitação do corpo docente ${ }^{1,2}$.

Para atuar na prática educativa universitária são necessários alguns requisitos como: formação específica e competências inerentes ao processo ensino aprendizagem, entre elas pode-se citar a prática reflexiva, que é uma das principais competências do docente, a qual deve ser utilizada a fim de instrumentalizar e analisar a atividade didática ${ }^{3}$.

0 educador deve considerar a complexidade do processo de educar como também a diversidade cultural dos educandos e das inovações pedagógicas que provocam mudanças nas formas de ensinar e aprender4. Esta adequação na formação docente deve ser um processo dinâmico e contínuo, impulsionando a busca de atualizações e estreitando a ligação com o desempenho da prática educativa 5 .

Neste sentido, é importante que o docente universitário não se restrinja ao campo de atuação para qual foi formado, deve buscar compreender o processo ensinoaprendizagem, sistematizar seu método de ensino e conhecer o plano e projeto pedagógico institucional como ponto de partida da sua atuação $0^{6,7}$.

Para atuar como professor no ensino superior, acima de tudo, é importante identificar-se com a profissão e assumir de forma competente a docência, reconhecer a sala de aula como espaço de aprendizagem em uma perspectiva interdisciplinar, promovendo a participação efetiva e mobilizando para a pesquisa, leitura, sistematização, análise, elaboração, síntese, crítica fundamentada e troca de experiências entre professor e aluno $^{5,7,8}$.

Competência na docência pode ser definida como capacidade de mobilizar recursos para desenvolver uma atividade e transformar a informação em conhecimento significativo, sendo relacionadas à formação do indivíduo, suas experiências, compreensão do mundo e cultura social na qual ele está envolvido ${ }^{5}$.

A noção de competência encontra-se associada à mobilização de recursos cognitivos para enfrentar um tipo de situação. Desta forma, a competência ou capacidade para mobilizar recursos constrói-se na formação e ao longo da atuação do professor em cada situação, passando por um conjunto de operações mentais complexas que permitem determinar e realizar certa ação ${ }^{8}$.

Competência docente constitui habilidade de organizar e dirigir situações de aprendizagem, administrar progressos, conceber e utilizar dispositivos tecnológicos nas estratégias pedagógicas com a finalidade de envolver alunos, refletir, trabalhar em equipe, enfrentar deveres e dilemas éticos, bem como, administrar a própria formação e capacitação ${ }^{8}$.

No Brasil, talvez uma das principais dificuldades da docência superior seja o fato do grande número de professores entrarem em sala de aula apenas com sua experiência profissional inicial e sem formação específica para atuarem no processo de ensino aprendizagem ${ }^{2,3}$. Essa falta de formação andragógica pode levar o docente a buscar maior qualificação ou levá-lo ao descontento fracasso ou frustração ${ }^{7,8}$.

0 ensino de Enfermagem no Brasil passou por diversas mudanças e modelos desde 19237. A evolução das reformas educacionais necessárias para atender a demanda do mercado de saúde e a autonomia das universidades em abrir cursos de 
enfermagem resultou no crescimento dos cursos de nível superior. Em 1964 existiam 39 cursos e em 1991 esse número passou para 106, um aumento de $171 \%$ em 27 anos. De 1991 a 2004, o número de cursos saltou para 415, representando um aumento de 291,5\% em apenas 13 anos 9,10 .

Considerando o período de 1991 a 2012, a expansão dos cursos no território brasileiro foi de 393\%, com aproximadamente 838 cursos de graduação em enfermagem. A região Sudeste alcança $43 \%$ do total de cursos de graduação em enfermagem no país, 36,73\% desse percentual só em São Paulo, seguida da região Nordeste com 24,12\%, região Sul com $14,61 \%$, Centro-Oeste com 10,96\% e Região Norte com 7,3\% ${ }^{11,12}$.

A enfermagem tornou-se uma das cinco profissões mais procuradas no Brasil e a situação de crescimento exponencial é dramática, pois os cursos costumam ter um alto custo para os alunos sem preocupação com a qualidade na formação. Com o aumento do número de cursos de graduação, há consequentemente uma necessidade de aumento do número de docentes habilitados para ministrar aulas no ensino superior impulsionando as instituições de ensino a estabelecerem critérios para contratação docente $^{9,10 .}$.

Dentro deste contexto, surge a necessidade de estudar como os docentes de cursos de graduação em enfermagem percebem a influência de fatores intrínsecos e extrínsecos nas suas competências como educadores. Dessa forma, o objetivo desse estudo é identificar os fatores (apoio institucional, habilidades interpessoais, capacidade didática pedagógica, abertura à inovação e apoio proativo à docência) que influenciam a percepção das competências para o exercício da docência.

\section{MÉTODO}

Estudo transversal quantitativo realizado em quatro instituições privadas de ensino superior sendo uma situada na cidade de
Guarulhos-SP e três na cidade de São Paulo, no período de abril a junho de 2014.

A amostra do estudo foi constituída por 45 docentes do curso de graduação em enfermagem que atenderam aos critérios de inclusão da pesquisa: (1) ser docente do curso de graduação em enfermagem indicado pelo coordenador de curso e (2) ser contratado pela instituição há pelo menos seis meses, pois a coleta de dados abordou assuntos que requerem afinidade com o ensino, ambiente e política institucional.

Foram aplicados dois instrumentos: (1) caracterização da amostra (sexo, idade, estado civil, titulação, atuação profissional no nível técnico, graduação, Stricto e Lato sensu, tempo de trabalho na instituição e local de trabalho) e (2) "Escala de fatores que influenciam na percepção das competências para o exercício da docência". Este instrumento é composto de 34 itens mensurados por meio de uma escala de Likert de seis pontos que varia de (1) discordo totalmente a (6) concordo totalmente. A escala possui cinco fatores: Apoio Institucional, Habilidades Interpessoais, Capacidade Didática Pedagógica, Abertura à Inovação e Apoio Proativo à Docência. 0 escore total pode variar de 34 a 204, sendo que quanto maior a pontuação, melhor a avaliação dos fatores que influenciam na percepção das competências para o exercício da docência ${ }^{13}$.

0 fator Apoio Institucional é descrito como a percepção dos docentes em relação ao suporte recebido pela instituição desde a sua qualificação profissional até o plano de carreira. 0 fator Habilidades interpessoais identifica a percepção do docente da habilidade interpessoal com o aluno em relação à troca efetiva do conhecimento favorecendo o relacionamento de confiança profissional entre docente e aluno. 0 fator Capacidade Didática Pedagógica relaciona-se com o processo ensino aprendizagem e capacidade de liderança didática do professor. 0 fator Abertura à Inovação está relacionado com a percepção do docente na busca de inovações, resoluções de problemas e entusiasmo no processo ensino aprendizagem 
para com o aluno. 0 fator Apoio Proativo à Docência revela a dimensão do pensamento do docente quanto à busca de diferentes formas de avaliação para acompanhar a aprendizagem do aluno e dificuldades e limitações do mesmo ${ }^{13}$.

Stricto Sensu é uma expressão em latim que se refere, no âmbito do ensino, ao nível de pós-graduação que confere ao aluno o título de mestre ou doutor em determinado campo do conhecimento. Lato sensu são cursos de pós-graduação de especialização e aprimoramento da formação acadêmica.

Tanto os professores quanto os dias e horários de coleta de dados na sala dos professores foram estipulados pela coordenação ou diretoria da graduação em enfermagem das instituições de ensino participantes.

Os professores foram instruídos a não preencherem o número do participante, essa numeração foi realizada posteriormente de forma aleatória (sem identificação do participante) e também foram orientados a devolverem os instrumentos de coleta e o Termo de Consentimento Livre e Esclarecido (TCLE) em pastas diferentes: em uma os instrumentos sem identificação e na outra o TCLE. Essa foi uma medida de proteção adotada pelos pesquisadores para diminuir o risco de identificação e constrangimento dos participantes.

Foram realizadas análises descritiva e inferencial dos dados. A correlação da idade e do tempo de trabalho com os escores de cada fator foi mensurada por meio do coeficiente de correlação de Spearman. A distribuição normal foi avaliada por meio do teste de KolmogorovSmirnov, e como não se observou aderência significativa à distribuição normal, os mesmos foram estudados quanto as variáveis sóciodemográficas por meio do Teste de MannWhitney ou Kruskal-Wallis. 0 nível de significância assumido foi em 5\% e o software utilizado para análise foi o Statistical Analysis Software - SAS 9.2.

0 desenvolvimento do estudo atendeu às normas nacionais e internacionais de ética em pesquisa envolvendo seres humanos e foi aprovado pelo Comitê de Ética e Pesquisa, parecer número 519.093.

\section{RESULTADOS}

Os 45 docentes tinham em média 44,2 anos $( \pm 9,3)$ e eram na maioria mulheres $(91,1 \%)$, casadas (73,3\%), especialistas $(60,0 \%)$ e enfermeiras (80\%) (Tabela 1).

Quanto à atuação profissional, todos os participantes ministravam aulas na graduação, a maioria não ministrava aulas no curso técnico $(57,8 \%)$, nem no Stricto Sensu $(75,6 \%)$ e nem no Lato sensu (91,1\%). 0 tempo de atuação na instituição predominantemente foi de mais que 10 anos (41,9\%) (Tabela 1$)$.

0 escore médio total das respostas dos participantes em relação à "Escala de fatores que influenciam na percepção das competências para o exercício da docência" foi de $170,6( \pm 13,7)$, mostrando que os docentes tiveram uma percepção de moderada para alta dos fatores que influenciam na percepção das competências necessárias para o exercício da docência (Tabela 2).

Considerando as médias e as variações de escore em cada um dos fatores, observou-se que Capacidade Didática Pedagógica e Abertura à Inovação obtiveram médias mais próximas da pontuação máxima, inclusive com os menores desvios-padrões $( \pm 2,3$ e $\pm 2,2$ respectivamente), ou seja, com uma menor variabilidade de respostas. Este dado mostra que, em geral, os professores percebem alta influência da maneira como eles relacionam-se com o processo ensino aprendizagem, da capacidade de liderança didática, da busca por inovações, resoluções de problemas e do próprio entusiasmo no aprendizado (Tabela 2). Já no fator Apoio institucional pode-se verificar que foi a média obtida mais distante da pontuação máxima, inclusive com maior desvio-padrão $( \pm 6,5)$, ou seja, maior variabilidade nas respostas.

Este dado mostra que em geral este fator obteve pior percepção dos docentes entrevistados em comparação com os outros 
fatores, o que significa que eles percebem instituição nas suas competências como baixa influência do suporte recebido pela docente (Tabela 2).

Tabela 1. Descrição das características da amostra estudada. São Paulo, 2014.

\begin{tabular}{|c|c|c|c|c|c|}
\hline Características da amostra & $\mathbf{N}$ & $\%$ & $\begin{array}{l}\text { Características da } \\
\text { atuação }\end{array}$ & $\mathbf{N}$ & $\%$ \\
\hline Sexo & & & Técnico & & \\
\hline Feminino & 41 & 91,1 & Não & 26 & 57,8 \\
\hline Masculino & 4 & 8,9 & Sim & 19 & 42,2 \\
\hline Idade & & & Graduação & & \\
\hline$<35$ & 8 & 17,8 & Não & 0 & 0,0 \\
\hline 35 a 44 & 14 & 31,1 & Sim & 45 & 100,0 \\
\hline 45 a 50 & 13 & 28,9 & & & \\
\hline$>50$ & 10 & 22,2 & Stricto sensu & & \\
\hline Média $(\mu) \pm \mathrm{DP}(\sigma)$ & 44,2 & $( \pm 9,3)$ & Não & 34 & 75,6 \\
\hline Estado Civil & & & Sim & 11 & 24,4 \\
\hline Casado & 33 & 73,3 & Lato sensu & & \\
\hline Solteiro & 7 & 15,6 & Não & 41 & 91,1 \\
\hline Viúvo & 1 & 2,2 & Sim & 4 & 8,9 \\
\hline Separado & 2 & 4,4 & Tempo de trabalho & & \\
\hline Divorciado & 2 & 4,4 & Até 3 anos & 12 & 27,9 \\
\hline Titulação & & & De 3 a 10 anos & 13 & 30,2 \\
\hline Doutor & 8 & 17,8 & Mais que 10 anos & 18 & 41,9 \\
\hline Mestre & 10 & 22,2 & $\operatorname{Média}(\mu) \pm \operatorname{DP}(\sigma)$ & $8,9 \pm 6,2$ & \\
\hline Especialista & 27 & 60,0 & Não referido $n=2$ & & \\
\hline \multicolumn{6}{|l|}{ Formação } \\
\hline Enfermeiro & 36 & 80,0 & & & \\
\hline Outros profissionais* & 8 & 17,8 & & & \\
\hline Enfermeiro** & 1 & & & & \\
\hline
\end{tabular}

Tabela 2. Escore total e por fator da "Escala de fatores que influenciam na percepção das competências para o exercício da docência”. São Paulo, 2014.

\begin{tabular}{lrrrrr}
\hline Fatores & $\begin{array}{c}\mathbf{N}^{\circ} \mathbf{d e} \\
\text { itens }\end{array}$ & $\begin{array}{r}\text { Variação } \\
\text { do escore }\end{array}$ & $\begin{array}{c}\text { Média } \\
(\boldsymbol{\mu})\end{array}$ & $\begin{array}{c}\text { Desvio- } \\
\text { padrão } \\
(\boldsymbol{\sigma})\end{array}$ & Mediana \\
\hline \hline Apoio Institucional & 8 & $8-48$ & 30,3 & 6,5 & 31,0 \\
Habilidades Interpessoais & 8 & $8-48$ & 43,2 & 4,1 & 44,0 \\
Capacidade Didática Pedagógica & 6 & $6-36$ & 33,4 & 2,3 & 34,0 \\
Abertura à inovação & 5 & $5-30$ & 27,6 & 2,2 & 28,0 \\
Apoio proativo à docência & 7 & $7-42$ & 36,1 & 4,1 & 37,0 \\
\hline Total & 34 & $34-204$ & 170,6 & 13,7 & 171,0 \\
\hline
\end{tabular}

Em relação à análise descritiva das respostas dos participantes em cada item da "Escala de fatores que influenciam na percepção das competências para o exercício da docência", optou-se pela avaliação dos extremos de resposta dos participantes ao invés da média em cada item justamente para observação dos itens em que os professores se manifestaram mais intensamente nos extremos de resposta.
Podem-se observar maiores frequências de resposta "concordo totalmente" nas questões $13(n=33 ; 73,3 \%), 18(n=33 ; 73,3 \%)$, $20 \quad(n=32 ; 71,1 \%)$ e $21 \quad(n=33 ; 73,3 \%)$ mostrando que o comprometimento com a educação, a organização no preparo das aulas e a didática são fatores que influenciam positivamente na competência do docente, bem como, a ética e o sentido de justiça fortalecem a imagem do professor para os 
alunos também, favorecendo a percepção das competências.

A resposta "discordo totalmente" foi mais frequente nas questões $2(\mathrm{n}=7 ; 15,6 \%), 3$ $(n=8 ; 17,8 \%), 5(n=7 ; 15,6 \%)$ e $6(n=5 ; 11,1 \%)$ mostrando que a atividade de pesquisa, os programas de aprimoramento e desenvolvimento profissional gerenciado pela área de Recursos Humanos das instituições de ensino, o plano de carreira e a política de
Recursos Humanos são fatores que precisam ser fortalecidos e estão sendo pouco estimulados e valorizados nas instituições estudadas.

$\mathrm{Na}$ correlação das variáveis numéricas idade e tempo de trabalho na instituição em relação às dimensões da "Escala de fatores que influenciam na percepção das competências para o exercício da docência" não se observou correlações significativas (Tabela 3).

Tabela 3. Correlação de variáveis idade e tempo de trabalho com os domínios da "Escala de fatores que influenciam na percepção das competências para o exercício da docência”. São Paulo, 2014.

\begin{tabular}{lcccc}
\hline & Idade & \multicolumn{3}{c}{ Tempo de trabalho } \\
& p-valor do r & r & p-valor do r & r \\
\hline \hline Apoio Institucional & 0,746 & 0,050 & 0,906 & 0,019 \\
Habilidades Interpessoais & 0,803 & $-0,038$ & 0,674 & 0,066 \\
Capacidade Didática & 0,855 & $-0,028$ & 0,307 & 0,160 \\
Pedagógica & & & & \\
Abertura à inovação & 0,605 & 0,079 & 0,756 & 0,049 \\
Apoio proativo à docência & 0,343 & 0,145 & 0,374 & 0,139 \\
\hline
\end{tabular}

Nota: Índice de correlação de Spearman.

$\mathrm{Na}$ associação das variáveis de caracterização categóricas com os fatores Apoio Institucional e Capacidade Didática Pedagógica não houve diferença estatisticamente significativa.

Houve diferença estatisticamente significativa no fator Habilidades Interpessoais na variável atuação na pós-graduação Lato sensu ( $\mathrm{p}$-valor=0,029) mostrando uma maior percepção dos docentes que atuam no Lato sensu das suas habilidades interpessoais com o aluno em relação à troca efetiva do conhecimento favorecendo o relacionamento de confiança profissional (Tabela 4). A atuação no Lato sensu, pela sua característica mais prática, pode ter influenciado positivamente na percepção das habilidades interpessoais dos docentes entrevistados.

Diferenças estatísticas significativas também foram encontradas na comparação das questões do fator Abertura à Inovação com a variável atuação do docente na pósgraduação Stricto Sensu (p-valor=0,049) mostrando menor percepção do docente que atua no Stricto Sensu na busca de inovações, resoluções de problemas e entusiasmo no processo ensino aprendizagem para com 0 aluno (Tabela 4).

Considerando o fator Apoio Proativo à Docência, houve diferença estatisticamente significante na variável atuação na pósgraduação Stricto Sensu (p-valor=0,049), este dado revela menor percepção do docente quanto à busca de diferentes formas de avaliação para acompanhar a aprendizagem do aluno, dificuldades e limitações (Tabela 4).

$\mathrm{Na}$ comparação entre o escore do domínio Habilidades Interpessoais e a atuação no Lato sensu, no grupo de professores que atuam, os limites superior e inferior obtidos neste domínio foram muito próximos 46 e 48, houve menor dispersão dos valores, a dispersão foi positivamente assimétrica e a mediana foi maior em comparação ao grupo de professores que não atuavam no Lato sensu (47,5 versus 43) (Figura 1A).

As comparações entre os escores dos fatores Abertura à Inovação e Apoio Proativo à Docência com a atuação no Stricto Sensu mostram características semelhantes, o grupo 
de professores que atuam no Stricto apresentaram menores valores de mediana e quartis 1 e 3 em ambas as comparações (Figura 1B e 1C).

Em uma tentativa de melhor entendimento das diferenças estatisticamente significativas, os participantes foram divididos em dois grupos. Os docentes que não atuavam no Stricto Sensu tinham em média 43,4 anos $( \pm 8,6)$, trabalhavam na instituição há em média 8,5 anos $( \pm 6,3)$ e a maioria era especialista (n=25; 73,5\%). Em comparação, os docentes que atuam no Stricto Sensu tinham em média 46,6 anos $( \pm 11,4)$, trabalhavam na instituição há 10,2 anos em média $( \pm 5,9)$ e a maioria era constituída por doutores $(n=7 ; 63,6 \%)$, ou seja, com maior média de idade, tempo de trabalho na instituição e titulação.

Estes docentes que atuam no Stricto Sensu apresentaram menor percepção das suas competências em relação à abertura à inovação e apoio proativo à docência, mostrando que talvez estas variáveis influenciem negativamente a percepção da facilidade de resoluções de problemas, entusiasmo no processo ensino aprendizagem e motivação para busca de diferentes formas de avaliação do aluno.

Tabela 4. Estudo dos domínios da "Escala" segundo variáveis categóricas. São Paulo, 2014

\begin{tabular}{|c|c|c|c|c|c|c|c|c|c|c|c|c|c|c|c|}
\hline \multirow[t]{2}{*}{ Variáxeis } & \multicolumn{3}{|c|}{$\begin{array}{c}\text { Apoio } \\
\text { Institucional }\end{array}$} & \multicolumn{3}{|c|}{$\begin{array}{c}\text { Habilidades } \\
\text { Interpessoais }\end{array}$} & \multicolumn{3}{|c|}{$\begin{array}{l}\text { Capacidade } \\
\text { Didática } \\
\text { Pedagógica }\end{array}$} & \multicolumn{3}{|c|}{ Abertura à inovação } & \multicolumn{3}{|c|}{$\begin{array}{l}\text { Apoio proativo à } \\
\text { docência }\end{array}$} \\
\hline & $\mu$ & $\sigma$ & $\begin{array}{c}\text { D- } \\
\text { valor }\end{array}$ & $\mu$ & $\sigma$ & $\begin{array}{c}\text { D- } \\
\text { valor }\end{array}$ & $\mu$ & $\sigma$ & $\begin{array}{c}\mathrm{D}- \\
\text { valor }\end{array}$ & $\mu$ & $\sigma$ & $\begin{array}{c}\text { D- } \\
\text { valor }\end{array}$ & $\mu$ & $\sigma$ & $\begin{array}{c}\text { D- } \\
\text { valor }\end{array}$ \\
\hline $\operatorname{Sexo}^{*}$ & & & 0,968 & & & 0,392 & & & 1,000 & & & 0,108 & & & 0,780 \\
\hline Feminino & 30,3 & 6,7 & & 43,3 & 4,0 & & 33,4 & 2,4 & & 27,8 & 2,2 & & 36,2 & 4,2 & \\
\hline Masculino & 30,3 & 5,1 & & 41,8 & 4,7 & & 33,5 & 2,4 & & 26,3 & 1,9 & & 35,5 & 3,7 & \\
\hline Estado Civil & & & 0,702 & & & 0,892 & & & 0,268 & & & 0,918 & & & 0,824 \\
\hline Casado & 29,7 & 6,7 & & 43,3 & 4,2 & & 33,6 & 2,1 & & 27,9 & 1,8 & & 36,4 & 3,8 & \\
\hline Solteiro & 30,9 & 6,9 & & 42,9 & 3,7 & & 33,0 & 2,5 & & 26,9 & 3,2 & & 35,4 & 4,8 & \\
\hline Viúvo & 31,0 & . & & 40,0 & . & & 31,0 & . & & 28,0 & . & & 37,0 & . & \\
\hline Separado & 36,0 & 4,2 & & 43,5 & 3,5 & & 30,5 & 5,0 & & 25,5 & 5,0 & & 32,5 & 6,4 & \\
\hline Divorciado & 32,0 & 7,1 & & 43,0 & 7,1 & & 35,5 & 0,7 & & 28,0 & 2,8 & & 36,5 & 7,8 & \\
\hline Escolaridade & & & 0,988 & & & 0,602 & & & 0,266 & & & 0,131 & & & 0,438 \\
\hline Mestre & 30,7 & 7,3 & & 44,0 & 4,1 & & 34,0 & 2,1 & & 27,9 & 2,5 & & 37,2 & 3,4 & \\
\hline Doutor & 29,6 & 8,9 & & 42,4 & 3,6 & & 31,9 & 3,2 & & 25,9 & 3,0 & & 34,4 & 4,9 & \\
\hline Especialista & 30,4 & 5,6 & & 43,1 & 4,2 & & 33,7 & 2,0 & & 28,1 & 1,5 & & 36,2 & 4,1 & \\
\hline Formação & & & 0,348 & & & 0,327 & & & 0,362 & & & 0,300 & & & 0,229 \\
\hline Enfermeiro & 30,6 & 6,7 & & 42,9 & 4,1 & & 33,4 & 2,4 & & 27,6 & 2,3 & & 35,8 & 4,1 & \\
\hline Enfermeiro com outra formação & 22,0 & - & & 48,0 & . & & 36,0 & - & & 30,0 & - & & 42,0 & - & \\
\hline Outros profissionais & 29,9 & 5,6 & & 44,0 & 3,9 & & 33,3 & 2,0 & & 27,4 & 1,5 & & 36,5 & 3,9 & \\
\hline \multicolumn{16}{|l|}{ Atuação profissional } \\
\hline Técnico* & & & 0,801 & & & 0,272 & & & 0,635 & & & 0,283 & & & 0,098 \\
\hline Não & 30,0 & 7,1 & & 42,6 & 4,0 & & 33,2 & 2,5 & & 27,2 & 2,6 & & 35,5 & 3,7 & \\
\hline Sim & 30,7 & 5,7 & & 44,0 & 4,2 & & 33,7 & 2,1 & & 28,2 & 1,5 & & 37,0 & 4,6 & \\
\hline
\end{tabular}




\begin{tabular}{|c|c|c|c|c|c|c|c|c|c|c|c|c|c|c|c|}
\hline Graduação* & & & 0,380 & & & 0,181 & & & 1,000 & & & 0,587 & & & 0,398 \\
\hline Não & 25,0 & . & & 48,0 & . & & 34,0 & . & & 29,0 & - & & 39,0 & . & \\
\hline & 30,4 & 6,5 & & 43,1 & 4,0 & & 33,4 & 2,4 & & 27,6 & 2,2 & & 36,0 & 4,1 & \\
\hline Pós-graduação Stricto sensu* & & & 0,926 & & & 0,561 & & & 0,159 & & & 0,049 & & & 0,049 \\
\hline Não & 30,5 & 5,9 & & 43,4 & 4,2 & & 33,8 & 2,1 & & 28,1 & 1,7 & & 36,8 & 3,9 & \\
\hline & 29,7 & 8,3 & & 42,6 & 3,6 & & 32,4 & 2,8 & & 26,2 & 2,9 & & 34,0 & 4,3 & \\
\hline Rós-araduacãa bato sensư & & & 0,648 & & & 0,029 & & & 0,231 & & & 0,238 & & & 0,267 \\
\hline Não & 30,2 & 6,4 & & 42,8 & 4,0 & & 33,4 & 2,1 & & 27,6 & 2,0 & & 36,0 & 3,9 & \\
\hline Sim & 31,5 & 7,9 & & 47,3 & 1,0 & & 33,8 & 4,5 & & 28,0 & 4,0 & & 37,5 & 6,6 & \\
\hline
\end{tabular}

Figura 1. Comparações entre a atuação dos docentes e os escores dos domínios da "Escala" que tiveram diferenças estatisticamente significativa. Figura 1A. Habilidades interpessoais e atuação no Lato Sensu. Figura 1B. Abertura à inovação e atuação no Stricto Sensu. Figura 1C. Apoio proativo à docência e atuação no Stricto Sensu. São Paulo, 2014.
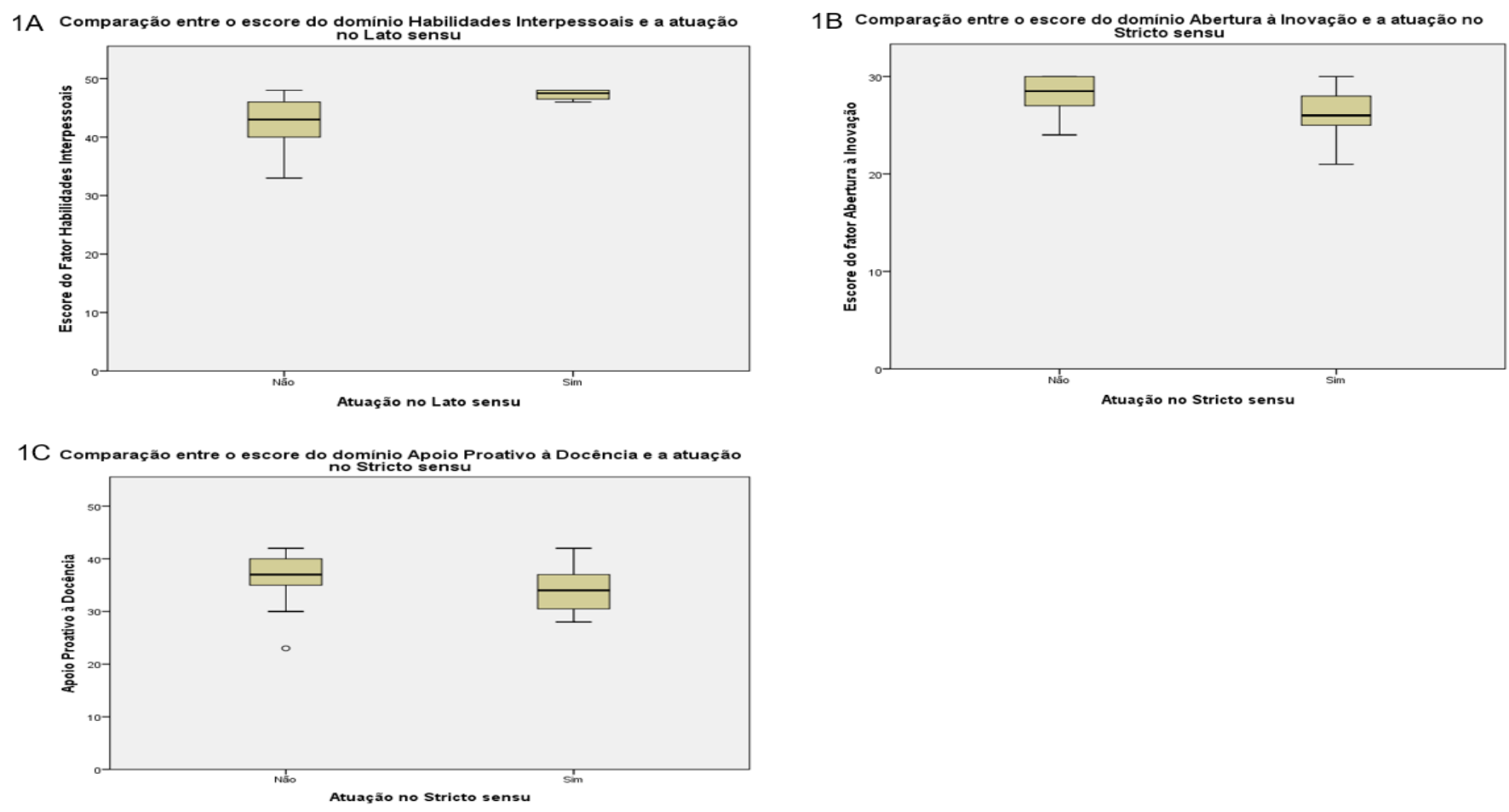

\section{DISCUSSÃo}

Resultados encontrados neste estudo sobre a importância da capacidade didática e da busca por inovações no desempenho e competências dos professores corroboram com outros estudos ${ }^{14-17}$ na qual a didática e inovação são considerados fatores convergentes e essenciais no processo de ensino aprendizagem.

Didática refere-se aos métodos e técnicas de ensino. Planejar o desenvolvimento das aulas propondo uma sequência das atividades de forma coerente considerando as limitações e capacidades dos alunos e com as metas a serem atingidas é um dos pontos mais importantes da capacidade didática do docente. Este planejamento deverá ser adaptado após cada atividade pedagógica, tendo em vista as atividades desenvolvidas e os resultados alcançados. 0 objeto de discussão deve ter ligação com o que os alunos já conhecem e o modo de condução deve constituir um progressivo desafio para os $\operatorname{mesmos}^{14,15}$. A didática aperfeiçoa-se com a inovação.

Inovação significa novas ideias nos avanços tecnológicos e científicos, sendo um conceito relacionado ao impacto da mudança gerada no ambiente e nas pessoas. A inovação 
no processo de ensino, além de intervir nos processos da prática andragógica, pode modificá-la e renová-la, exigindo um esforço deliberado do professor e ações persistentes para melhorar a prática educativa ${ }^{16}$.

0 professor aberto à inovação incorpora mais facilmente as mudanças tecnológicas e comportamentais na área da educação. Abertura à inovação pode ser considerada uma competência facilitadora que é capaz de estimular a busca do conhecimento, o interesse e o envolvimento dos alunos, uma vez que estes professores estão mais perto e abertos às novas tecnologias de comunicação e informação ${ }^{17}$.

Nesta perspectiva, inovação também é essencial para permitir ao aluno a oportunidade de aprender de forma autônoma, experimentar diferentes vivências andragógicas que o estimule a construir seu conhecimento a partir da descoberta. Entretanto, muitos professores têm dificuldades de buscar soluções inovadoras para o ensino por inúmeros motivos.

Neste estudo, docentes que atuam no Stricto Sensu apresentaram menor percepção das suas competências em relação à abertura à inovação e apoio proativo à docência. Algumas características do trabalho neste nível de atuação, tais como necessidade de uma carreira profissional direcionada ao acadêmico, experiência em pesquisa, estudo e atualização constante, maior tempo de trabalho e dedicação na produção de conhecimento, podem ter influenciado negativamente a percepção destas habilidades, pois o professor pesquisador pode afastar-se da sala de aula e da prática da profissão, além das evidentes diferenças entre as gerações em relação ao uso das tecnologias da informação e comunicação.

Tecnologia da Informação e Comunicação (TIC) pode ser definida como um conjunto de recursos tecnológicos, informática, computador, internet, CD-ROM, hipermídia, multimídia e de outros recursos de linguagens digitais que podem colaborar significativamente para tornar o processo de educação mais eficiente e mais eficaz ${ }^{18}$.

0 uso das tecnologias requer maior acesso à tecnologia, domínio das evoluções tecnológicas e planejamento adequado ${ }^{19}$. Em geral, professores mais conservadores ou acostumados com a modalidade presencial de ensino têm baixa tendência a inovar e utilizam as TIC mais simples na sala de aula ${ }^{20}$.

Frente à necessidade de atualização para acompanhar as demandas das novas gerações de alunos, muito mais acostumados com novas tecnologias de informação e comunicação, surge à responsabilidade do apoio institucional nesse processo. $\mathrm{Na}$ medida em que a inovação tecnológica invade 0 ambiente de ensino, as instituições precisam preparar-se para atender às novas demandas. No entanto, 0 apoio institucional foi mencionado neste estudo pelos professores como um fator com baixa influência sobre a competência docente.

Um estudo ${ }^{21}$ apresentou resultados semelhantes ao presente trabalho, evidenciando uma fragilidade na relação professor e instituição de ensino. 0 objetivo do estudo foi verificar se a função Recursos Humanos das universidades privadas brasileiras estimula o desenvolvimento das competências do professor. Para isso, foi realizada uma pesquisa qualitativa por meio de entrevistas com os principais executivos das universidades e uma pesquisa quantitativa por meio de um questionário fechado e autoaplicável com 60 itens (um instrumento piloto da "Escala de fatores que influenciam na percepção das competências para o exercício da docência") com 282 professores. Os resultados revelaram que os professores reconhecem as competências necessárias para o exercício da docência, por outro lado, as universidades não percebem ações e práticas de Recursos Humanos que facilitam o desenvolvimento dessas competências, propiciando um diferencial competitivo no ambiente acadêmico.

Outro aspecto interessante abordado no estudo mencionado ${ }^{21}$ é que as universidades 
particulares, sob a ótica de seus representantes, desconhecem o potencial da área de recursos humanos, em que se exercitam apenas atividades burocráticas de seu efetivo. Mesmo distantes da realidade de atuação dos recursos humanos, os dirigentes valorizam sua função como articuladores de estratégias de desenvolvimento de pessoas, ficando clara a falta de ações pragmáticas para implementar políticas e práticas de recursos humanos que proporcionem respostas eficazes para alcançar os objetivos.

0 apoio institucional na prática docente pode influenciar diretamente sua atuação, visto que se relaciona às condições de trabalho, possibilidade de capacitação que vai desde o incentivo a pesquisa até cursos de capacitação à docência, destinação de hora atividade pedagógica e plano de carreira dentro da instituição de ensino ${ }^{22,23 .}$

0 Projeto Pedagógico Institucional (PPI), que é parte integrante do Plano de Desenvolvimento Institucional (PDI) das instituições de ensino, deve conter no seu regimento interno as atividades e ações que possam evidenciar o apoio e ou incentivo à prática de seus docentes, com a finalidade de apoia-los em sua qualificação didáticopedagógico, tendo em vista a otimização do ensino desenvolvido no cumprimento de sua missão, visão e valores ${ }^{23}$, porém o docente também tem que se preocupar com o seu desenvolvimento intelectual e buscar novos conhecimentos muitas vezes fora da sua instituição de trabalho, para contribuir na troca de conhecimento.

0 gestor educacional precisa, por princípio, apoiar e incentivar os professores que desejam continuar sua formação. É necessário dar o mínimo de condições para isso, como dispensa para que ele possa participar de aulas presenciais em cursos voltados à prática docente, redução da carga horária na sala de aula para que ele possa estudar e aprimorar-se, entre outras ações. Há instituições de ensino que já possuem essa prática de apoio, mas, a iniciativa do professor é o ponto de partida.
Outro aspecto importante é que a formação do docente é algo que precisa ser eficaz e bem planejada, inclusive em níveis governamentais. A partir da Lei de Diretrizes e Bases da Educação no 9.394 de 20 de dezembro de $1996^{22}$, o contexto do ensino superior brasileiro iniciou um processo de revitalização de seus objetivos que tinham como finalidade imediata que os programas de pós-graduação Stricto Sensu assumissem o compromisso de formação, capacitação e preparação dos docentes de nível superior.

Assim, o ensino de pós-graduação é visto como principal veículo para criação de novos conhecimentos, que não envolva somente a transcrição do conhecimento e troca de experiência, mas também o de assumir o desenvolvimento da ciência, tecnologia e, estratégias didáticas em prol da formação de docentes para o ensino superior ${ }^{24}$.

A legislação brasileira determina que a preparação para o exercício do magistério superior seja feita, prioritariamente, em programas de mestrado e doutorado. Os programas de pós-graduação Stricto Sensu desenvolvem atividades fundamentalmente voltadas à formação de pesquisadores, em prejuízo da necessária formação pedagógica de profissionais para o exercício do magistério superior. É muito comum a interpretação, talvez equivocada, de que o bom pesquisador é, necessariamente, um bom professor, justificando as atividades prioritárias de formação de pesquisadores pelos programas de pós-graduação Stricto Sensu 23,25.

Há percepções que denotam que a preocupação pela formação docente em nível de pós-graduação, especialmente no setor privado, tem cunho muito mais econômico do que pedagógico, na medida em que os indicadores de qualidade da educação superior, notadamente do corpo docente, estão centrados na titulação, regime de trabalho e produção docente. A titulação docente, avaliada isoladamente e sob o aspecto quantitativo, pode não causar nenhum impacto sobre a almejada qualidade da educação superior, mas assegura cumprimento de 
requisitos mínimos para o credenciamento ou recredenciamento institucional 23,25 .

Os achados do presente estudo e seu cotejamento com a literatura suscitam fatores e elementos que podem influenciar na percepção da competência dos docentes, entretanto, fica evidente que mais do que o fortalecimento dos fatores individuais, há uma necessidade do fortalecimento da relação entre eles, tanto de fatores intrínsecos quanto externos, que poderão contribuir para uma percepção mais positiva das competências tão importantes para o exercício da docência.

\section{CONCLUSÃO}

Os docentes participantes deste estudo tiveram uma percepção de moderada para alta da influência dos fatores em sua competência docente. Por sua vez, os professores percebem, alta influência da capacidade didática e da busca por inovações e baixa influência do suporte institucional.

Comprometimento com a educação, organização no preparo das aulas e a didática foram fatores que influenciaram positivamente na competência do docente, bem como, a ética e o sentido de justiça que fortalecem a imagem do professor.

Não estar relacionado à atividade de pesquisa e aos programas de aprimoramento, bem como, o desenvolvimento profissional gerenciado pela área de Recursos Humanos das instituições, o plano de carreira e a política de recursos humanos foram fatores percebidos negativamente.

Os professores que atuam no Lato sensu tiveram melhor percepção das suas habilidades interpessoais com os alunos; os que atuam no Stricto Sensu tiveram menor percepção em relação a suas habilidades de busca por inovações no ensino e apoio proativo ao aluno.

\section{REFERENCIAS}

1. Santos JMC, Albuquerque MOA. Docência superior: formação e competências para o exercício da profissão. In: IV Fórum Internacional de
Pedagogia, FIPED; 2012; Parnaíba, PI. Parnaíba, PI: UFPI; 2012. p.1-14.

2. Pimenta SG, Anastasiou LGC. Docência no ensino superior. São Paulo: Cortez; 2002.

3. Huneeus FC. Os desafios de formar bons professores. (Entrevista com Almeida C). Rev Gest Educ. 2011; 6(72).

4. Pierantoni CR, França T, Ney MS, Oliveira MV, Chris T, Santos MR, et al. Avaliação de desempenho: discutindo a tecnologia para o planejamento e gestão de recursos humanos em saúde. Rev Esc Enferm USP. 2011; 45(Esp):1627-31.

5. Freire P. Pedagogia da autonomia: saberes necessários à prática educativa. 25ed. Rio de Janeiro: Paz e Terra; 2008.

6. Ministério da Educação (Br). Diretrizes curriculares nacionais do curso de graduação em Enfermagem [Internet]. Brasília (DF): Ministério da Educação; [2001] [citado em 12 jul 2013]. Disponível em: http://portal.mec.gov.br/cne/arquivos/pdf/Enf.pd f.

7. Cogo ALP, Pedro ENR, Silva APSS, Shatkoski AM, Catalan VM, Alves RHK. Objetivos educacionais digitais em enfermagem: avaliação por docentes de um curso de graduação. Rev Esc Enferm USP [internet]. 2009 [citado em 08 set 2015]; 43(2):295-9. Disponível em: http://www.scielo.br/pdf/reeusp/v43n2/a06v43n 2.pdf.

8. Santos J. Educação profissional \& práticas de avaliação. Rio de Janeiro: SENAC; 2010.

9. Franco AP. Ensino superior no Brasil: cenário, avanços e contradições. J Polit Educ. 2008; (4):5363.

10. Faria JIL, Casagrande LDR. A educação para o século XXI e a formação do professor reflexivo na enfermagem. Rev Latinoam Enferm. [Internet]. 2004 [citado em 08 set 2014]; 12(5):821-27. Disponível em: http://www.revistas.usp.br/rlae/article/viewFile/ $1947 / 2012$.

11. Pereira FJR, Santos SR, Silva CC. Política de formação inclusiva: percepção de gestores sobre processo de mudanças em instituições de ensino superior. Rev Bras Enferm. [Internet]. 2011 [citado em 08 set 2015]; 64(4):711-6.. Disponível em: http://www.scielo.br/pdf/reben/v64n4/a13v64n 4.pdf.

12. Erdmann AL, Fernandes JD, Texeira GA. Panorama da educação em enfermagem no Brasil: 
graduação e pós-graduação. Enferm Foco. 2011; 2(supl):89-93.

13. Nassif VMJ, Hanashiro DMM, Torres RR. Fatores que influenciam na percepção das competências para o exercício da docência. Rev Bras Educ [Internet]. 2010 [citado em 08 set 2015]; 15 (44):364-79. Disponível em: http://www.scielo.br/pdf/rbedu/v15n44/v15n44 a12.pdf.

14. Mitre SM, Batista RS, Mendonça JMG, Pinto NMM, Meirelles CAB, Porto CP, et al. Metodologias ativas de ensino-aprendizagem na formação profissional em saúde: debates atuais. Ciênc Saúde Coletiva. 2008; 13(sup2):2133-44.

15. Silveira RLBL. Competências e Habilidades pedagógicas. Rev Iberoam Educ [Internet]. 2001. [citado em 08 set 2014]. Disponível em: http://www.rieoei.org/deloslectores/490Barros.p df.

16. Carbonell J. A aventura de inovar: a mudança na escola. Porto Alegre: Artmed; 2002.

17. Prety L, Jorge V. Relações interpessoais no ambiente escolar sob a visão de professores de ciências e matemática. In: X Encontro Gaúcho de Educação Matemática; 2009; Ijuí, RS. Ijuí, RS: UNIJUÍ; 2009. p.1-13.

18. Massetto MT. Mediação pedagógica e o uso da tecnologia. In: Moran JM, Massetto MT, Behrens MA. Novas tecnologias e mediação pedagógica. 12ed. Campinas: Papirus; 2000.

19. Pimentel NM. A política nacional de educação à distância no ensino superior: elementos para um quadro de análises das relações com o ensino presencial. Pesqui Debate Educ. [Internet]. 2013 [citado em 05 maio 2015]; 3(1):50-66. Disponível em:

http://www.revistappgp.caedufjf.net/index.php/re vista1/article/view/47/37.
20. Korelo JC, Prado PHM, Silva DML. Escolha e adoção de tecnologias de informação e comunicação na educação. Rev Adm Inov. [Internet]. 2010 [citado em 10 maio 2015]; 7(2):80-103. Disponível em: http://www.revistas.usp.br/rai/article/view/7917 $1 / 83243$.

21. Hanashiro DMM, Nassif VMJ. Competências de professores: um fator competitivo. Rev Bras Gest Neg. 2006; 8(20):45-56.

22. Presidência da República (Brasil) LEI № 9.394, 20 de Dezembro de 1996. Dispõe sobre a carga horária dos docentes da rede estadual e outras de ensino [Internet]. DOU, Brasília (DF), 23 dez 1996 [citado em 07 set 2014]. Disponível em: http://www.planalto.gov.br/ccivil_03/leis/19394.h tm.

24. Universidade Potiguar. Programa de apoio a capacitação docente [Internet]. Natal: Edunp, 2008 [citado em 08 set 2014]. (Coleção Documentos Normativos da UnP; Série Verde; Gestão de Recursos Humanos). Disponível em: http://unp.br/arquivos/pdf/institucional/docinsti tucionais/pacd.pdf.

25. Barreto MO, Martinez AM. Possibilidades criativas de professores em cursos de pósgraduação Stricto Sensu. Estud Psicol. 2007; 24(4):463-73.

26. Melo PA, Luz RJP. Formação docente no Brasil [Internet]. Florianópolis, SC: IESALC; 2005 [citado em 22 maio 2015]. Disponível em: http://www.oei.es/docentes/info_pais/informe_fo rmacion_docente_brasil_iesalc.pdf.

\section{CONTRIBUIÇÕES}

Todas as autoras trabalharam igualmente nas diversas etapas do desenvolvimento da pesquisa e da redação do artigo.

\footnotetext{
Como citar este artigo (Vancouver):

Santos CCM, Puggina ACG, Pereira LL. Fatores que influenciam a percepção de professores de enfermagem das competências na docência. REFACS [Online]. 2016 [citado em (inserir dia, mês e ano de acesso)]; 4(2). Disponível em: (link de acesso). DOI: 10.18554/refacs.v4i2.1640.

\section{Como citar este artigo (ABNT):}

SANTOS, C. C. M.; PUGGINA, A. C. G.; PEREIRA, L. L. Fatores que influenciam a percepção de professores de enfermagem das competências na docência. REFACS, Uberaba, MG, v. 4, n. 2, p. 86-97, 2016. Disponível em: (link de acesso). DOI: 10.18554/refacs.v4i2.1640. Acesso em: (inserir dia, mês e ano de acesso).

Como citar este artigo (APA):

Santos, C. C. M.; Puggina, A. C. G. \& Pereira, L. L. (2016). Fatores que influenciam a percepção de professores de enfermagem das competências na docência. REFACS, 4(2), 86-97. Recuperado em: (dia), (mês), (ano) de (link de acesso). DOI: 10.18554/refacs.v4i2.1640.
} 
